\title{
Influence of Chitosan Characteristics in the Microencapsulation of Essential Oils
}

\section{Manuel José Lis Arias ${ }^{1}{ }^{(1)}$, Arianne López ${ }^{1}$, Mercè Vilaseca ${ }^{1}$, Betina Vallès $^{1}$, Remedios Prieto ${ }^{1}$, Mercedes Simón ${ }^{1}$ José Alexandre Borges Valle ${ }^{2}$, Rita De Cássia Siqueira Curto Valle ${ }^{2}$, Fabriccio Maesta Bezerra ${ }^{3}$, Jordi Puiggalí Bellalta ${ }^{4}$}

${ }^{1}$ INTEXTER-UPC, Terrassa, Spain; ${ }^{2}$ Universidade Federal de Santa Caterina, Blumenau, Brasil; ${ }^{3}$ Federal Technological University og Paraná, Apucarana, Brasil; ${ }^{4}$ Universidad Politecnica de Catalunya, EEBE, Barcelona, Spain

Correspondence to: Manuel José Lis Arias, manuel-jose.lis@upc.edu Keywords: Microcapsules, Biopolymer, Antimicrobial, Biofunctional Textiles Received: November 4, 2020 Accepted: March 19, $2021 \quad$ Published: March 22, 2021

Copyright $\odot 2021$ by author(s) and Scientific Research Publishing Inc.

This work is licensed under the Creative Commons Attribution International License (CC BY 4.0). http://creativecommons.org/licenses/by/4.0/

\section{(c) (i) Open Access}

\section{ABSTRACT}

The fight against nosocomial infections in hospitals, has promoted the use of microencapsulated essential oils on medical wearing uniforms. These types of microcapsules can be improved with the use of antimicrobial polymers in the shell structure. Chitosan is one of the most used biopolymers and the effectiveness of the treatment can be increased with the combination of different molecular weight chains of chitosan. This modification in the composition of shell structure allows controlling the rate of hydrolysis and, therefore the amount of its cationic form. The main objective of this work is to define a methodology to get microcapsules with different shell compositions, using surfactants as stabilizers in their first step. Once they have been obtained, these microcapsules will be fixed into textile substrates with the objective to use these tissues as surgical and medical clothes to spread the antibacterial effect, in sanitary staff, as well as in the own patient. In the process of microencapsulation the molecular weight distribution of polymers, influences strongly the delivery mechanisms of the active principle, as well as the chemical characteristics of the textile substrate used in every case. In this work, several chitosan biopolymers have been checked. Structural changes in the stabilization first step and the influence of the cross-linking extension have been related with the final antibacterial effect when fixed on cotton substrates.

\section{INTRODUCTION}

When a patient is admitted into a hospital, what results are more dangerous for him/her, their hospital stays or their own admissions? Some authors ensure that there are risks of infection in surgical rooms 
and some devices and measures have been taken to solve them $[1,2]$. Today, more than $15 \%$ of the people who enter the operating room are infected by nosocomial diseases, according to Jose Maria's work (2015) [3]. In hospitals the main method of transmission is by people wearing a gown in contact with the skin. According to several studies, textile industry has been incorporating microencapsulation techniques for specific and technical products [4].

Microencapsulation technique is known as a process by which particles of liquid or solid material, are coated by a continuous film of a polymeric material $[5,6]$. They are formed by means of a coating membrane, to protect the material to be encapsulated from foreign agents [7-9].

It is an efficient method to protect active compounds, which can be essential oils or fragrances, to provide them with durability, when applying, to temperature or light $[10,11]$. In many areas where microcapsules are used, it has caused a significant and evident increase in the last decade. Microcapsules have the characteristic of providing environmental protection and controlling release characteristics [7].

The textile substrates can be functionalized with chitosan microcapsules through different treatments, which allows them to be placed inside the fiber structure permanently [6]. In the last decades, the functional properties of textile materials have been studied and, one of the problems that has emerged is the growth of bacteria and other microorganisms on the textile surface $[12,13]$. After performing different strategies to inhibit antimicrobial growth, chitosan was found to be one of the most innovative alternatives as it is a natural, biocompatible, and biodegradable polymer [6]. Polymers, in general, particularly as part of microcapsules or nanoparticles, are considered, as a promising alternative for controlled release and increased drug delivery efficacy [12].

Chitosan is a polysaccharide that is a natural macromolecule derived from agricultural materials such as cellulose or crustacean waste [13]. It is considered a highly reactive polysaccharide because it is hydrox$\mathrm{yl}$ and amine group [14,15]. Although at that moment it can be obtained from mushrooms, it is a natural biopolymer derived from chitin, produced by a process of $n$-deacetylation by chemical methods on alkaline solutions at high temperatures [16-18]. At $\mathrm{pH}$ values lower than 6.3 the amino groups are free and protonated, thus becoming a cationic polyelectrolyte soluble in water, while when $\mathrm{pH}$ values are higher these amino groups are deprotonated and then, chitosan loses its charge becoming insoluble in aqueous media [19-21]. Another interesting property to be considered is the final degree of deacetylation obtained. The degree of deacetylation determines the number of free amino groups in the polymer chain and depending on their molecular weight and degree of deacetylation, applications of antibacterial activity will be affected [22-25].

In this work, microcapsules are made by means of complex coactivity. It is known as the phenomenon produced in a chitosan solution in an alkaline medium that helps the precipitation and phase separation of this biopolymer. By means of the complex coacervation technique, polymer solutions are obtained from the interactions of two oppositely charged polymers $[25,26]$.

The main objective of this study is to make microcapsules of essential oils using different types of chitosan to establish the relationship between the chemical structure and characteristics of the chitosan used and the final antibacterial properties when used as shell structure in the primary layer. Sampling the different types of biopolymer will allow us to compare how these particular properties would affect different possible applications.

\section{EXPERIMENTAL PROCEDURE}

\subsection{Materials}

Chitosan (Low molecular weight) from Sigma Aldrich, Chitosan of different chemical characteristics (Viscosities between $65-173 \mathrm{cP}$ ), supplied by Biomedical Chitosan (Australia), chitosan water soluble (20 $\mathrm{cP})$ and acidsoluble chitosan (600 cP) (CHIBIO, China), Gum Arabic from Sigma Aldrich were used as shell-forming materials. Lavender essential oil was used as core agent, surfactants (Tween 20 and Sodium Lauryl Sulfate LSS), Tannic Acid, $0.1 \mathrm{~N}$ acetic acid used to dissolve chitosan, was purchased from Sigma Aldrich. Citric Acid and Monobasic Sodium Phosphate Monohydrate were used in the grafting reaction 
and purchased to PANREAC (Spain). Textile substrate, cotton CN-11 (100\%, $\left.170 \mathrm{~g} \cdot \mathrm{m}^{-2}\right)$, supplied by Test materials (Netherlands).

\subsection{Microcapsules Production}

The method used is the complex coacervation between Arabic gum and chitosan. All the samples have been made following the process proposed by some authors [27] with slight modifications.

The protocol can be divided into three different steps: stabilization of the essential oil drops in aqueous media, the incorporation of the first layer of chitosan (alone or combined) and the addition of the Arabic gum second layer.

First layer will be a combination of different chitosan molecular weight and/or with soluble chitosan in order to establish which is the trigger mechanisms involved in the delivery of the active compounds of lavender essential oil.

The following protocol, defines the different steps involved in the complex formation:

- $\quad$ Nucleation of the active principle (essential oil, in this case)

- First polymer layer formation and activation

- $\quad$ Final layer construction using a combination of polymers and cross-linking agents

A $1 \%(\mathrm{w} / \mathrm{v})$ chitosan solution is prepared and left in agitation for 15 hours. The Arabic gum solution is prepared at $2 \%(\mathrm{w} / \mathrm{v})$ in deionized water under stirring conditions for 2 hours and at 40 degrees.

After, different concentrations of lavender oil and different concentrations of surfactants are added to the former mixture under mild stirring conditions (IKA, T-25). The different concentrations can be seen in Table 1. Check and give to $\mathrm{pH} 3$ with hydrochloric acid, if necessary for complex coacervation to occur. Finally, it is necessary to keep the mixture in a gel bath to reach 5 degrees. Keeping the temperature constant, add 2\% (w/v) tannic acid, and let it under mild stirring conditions for 3 hours.

\subsection{Antimicrobial Test}

The aqueous mixture was applied to the textile substrate using padding system (BENZ-Pilot plant) that is the most used industrial procedure in textile industry. The pressure between rolls has been regulated to get $80 \%$ of impregnation.

The method to check the antibacterial activity provided by the tissue, is AATCC 147 (American Association of Textile Chemists and Colorists). It is a useful method for an approximate and qualitative estimation of the growth of the microorganism when contacting the sample. Following the instructions of several authors [28, 29], the impregnated sample is incubated in contact with the agar for 24 hours at 37 degrees to see whether the bacteria have grown. ATCC method proposes the use of two different bacteria, Staphylococcus aureus (gram positive) and Eschericcia coli (gram positive).

\subsection{Optical Microscopy}

The samples were observed with different magnification lenses of $5 \times, 10 \times, 20 \times$ and $40 \times$. All the photos were taken with the Olympus BX43F optical microscope which is connected to a high-resolution digital camera (ProgRes 3, Germany).

\subsection{Particle Size}

The measurement (Nano-sizer Malvern, EEUU) is based on laser scattering at diluted solutions where the mobility of particles is allowed, thanks to the electrophoretic properties generated on the particles, size of them is obtained. In this work, results shown are the average media.

\subsection{Zeta Potential}

Each particle dispersed in a solution, is surrounded by oppositely charged ions forming a layer at the 
Table 1. Composition of different samples prepared.

\begin{tabular}{|c|c|c|c|c|c|c|c|c|c|c|}
\hline \multirow{2}{*}{ Samples } & \multicolumn{7}{|c|}{ Chitosan polymers } & \multicolumn{2}{|c|}{ Surfactants } & \multirow{2}{*}{$\begin{array}{c}\begin{array}{c}\text { Active } \\
\text { principle }\end{array} \\
\text { Lavender } \\
\text { Oil (mL) }\end{array}$} \\
\hline & $\begin{array}{c}\text { Low } \\
\text { Molecular } \\
\text { Weight (\%) }\end{array}$ & $\begin{array}{c}95 / 150 \\
\text { (a) }\end{array}$ & $\begin{array}{c}95 / 100 \\
\text { (b) }\end{array}$ & $\begin{array}{l}90 / 50 \\
\text { (c) }\end{array}$ & $\begin{array}{l}90 / 100 \\
\text { (d) }\end{array}$ & $\underset{(\mathrm{e})}{\text { Soluble }}$ & $\begin{array}{c}600 \mathrm{cP} \\
\text { (f) }\end{array}$ & $\begin{array}{c}\text { Tween } \\
20(\mathrm{~mL})\end{array}$ & $\begin{array}{l}\text { LSS } \\
(\mathrm{mL})\end{array}$ & \\
\hline 1 & & 1 & & & & & & 2 & & 2 \\
\hline 2 & & 1 & & & & & & 2 & & \\
\hline 3 & & 1 & & & & & & 1 & 1 & 2 \\
\hline 4 & & 1 & & & & & & 1 & 1 & \\
\hline 5 & & & 1 & & & & & 2 & & 2 \\
\hline 6 & & & 1 & & & & & 2 & & \\
\hline 7 & & & 1 & & & & & 1 & 1 & 2 \\
\hline 8 & & & 1 & & & & & 1 & 1 & \\
\hline 9 & & & & 1 & & & & 2 & & 2 \\
\hline 10 & & & & 1 & & & & 2 & & \\
\hline 11 & & & & 1 & & & & 1 & 1 & 2 \\
\hline 12 & & & & 1 & & & & 1 & 1 & \\
\hline 13 & & & & & 1 & & & 2 & & 2 \\
\hline 14 & & & & & 1 & & & 2 & & \\
\hline 15 & & & & & 1 & & & 1 & 1 & 2 \\
\hline 16 & & & & & 1 & & & 1 & 1 & \\
\hline 17 & 0.625 & & & & & 0.375 & & 2 & & 2 \\
\hline 18 & 0.625 & & & & & 0.375 & & 2 & & \\
\hline 19 & 0.625 & & & & & 0.375 & & 1 & 1 & 2 \\
\hline 20 & 0.625 & & & & & 0.375 & & 1 & 1 & \\
\hline 21 & & & & & & & 1 & 2 & & 2 \\
\hline 22 & & & & & & & 1 & 2 & & \\
\hline 23 & & & & & & & 1 & 1 & 1 & 2 \\
\hline 24 & & & & & & & 1 & 1 & 1 & \\
\hline
\end{tabular}

(a) Degree of diacetylation (DDA) 97.5\%; (b) DDA 97.5\%; (c) DDA 93\%; (d) DDA 92.8\%; (e) Water soluble; (f) DDA 85\% - 98\%. 
interface. The orientation, and intensity of the molecular interaction of the molecules in this interface will create an electrical field. Therefore, the zeta potential is a function of the charged surface of a particle, and shows the stability of these colloidal particles in the medium.

\subsection{Percentage by Weight in the Tissue}

The method used for impregnation of the different samples to the tissue is based on the same as used by Yang, $\mathrm{Z}$ et al. and Fan, F et al. [22, 30].

A solution is prepared with each of the samples containing $10 \%(\mathrm{w} / \mathrm{v})$ of the dissolution of the microcapsules, $3 \%(\mathrm{w} / \mathrm{v})$ citric acid and 3\% (w/v) monobasic sodium monohydrate (catalyst). With the help of a foulard, samples can be impregnated to cotton at a pressure between rolls of 0.5 bar. Samples led to dry at environmental conditions until constant weight.

This formula is used to calculate the percentage by weight in the tissue:

$$
\% \text { Tissue weight }=\frac{\text { Tissue weight }(\mathrm{f})-\text { Tissue weight }(0)}{\text { Tissue weight }(0)}
$$

where: Tissue weight $(0)$ is the weight of the fabric before permeation in grams. Tissue weight (f) is the weight of the tissue after impregnation in grams.

\section{RESULTS AND DISCUSSION}

\subsection{Optical Microscopy}

The different results have been divided into several groups in order to establish correlations between composition and final properties.

In the first case, as can be seen in Figure 1, samples [F1-F4], several microcapsules obtained using chitosan (a) and (c) (see Table 1). Samples contain the Lavender essential oil and Tween 20, but in different molar ratios. The presence of the non-ionic surfactant allows the formation of size reduced microcapsules. There is a micelles formation process that provides stability to the system and reduces size of the colloidal structure formed. When no active ingredient is used, the surfactant is dispersed at the interface of the microcapsule with the various polymers (Figure 1(F2)). The presence of Lavender oil compounds and the second surfactant (LSS), affects the size of the aggregate, in this case it expands, but the active ingredient with the surfactants still forms micelles (Figure 1(F3)).

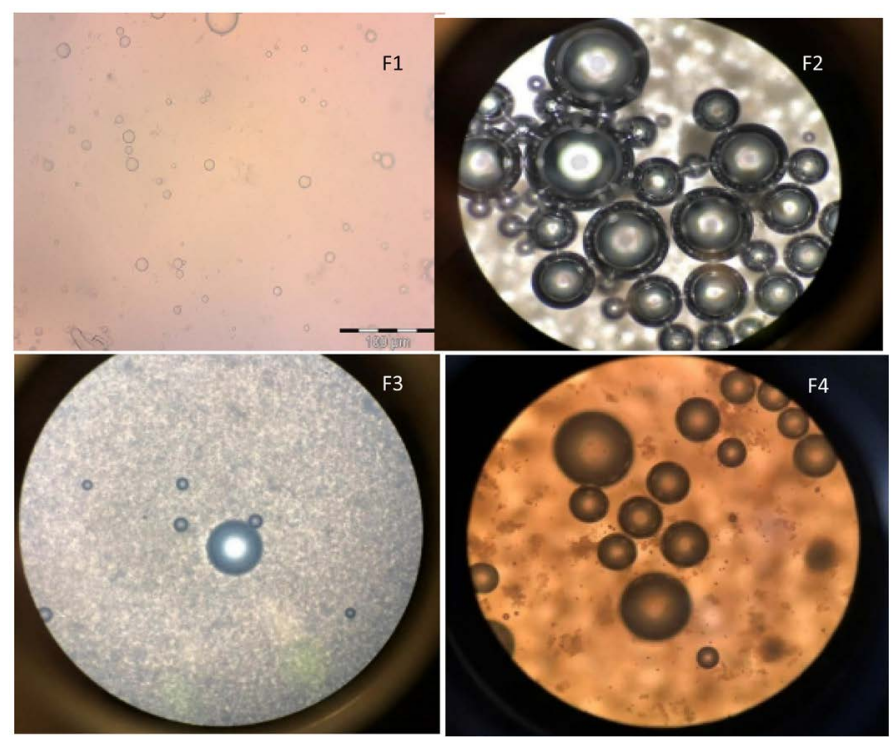

Figure 1. F1: Sample 1 (5x); F2: Sample 10 (10x); F3: Sample 3 (5x); F4: Sample 12 (10x). 
Results obtained with the addition of soluble chitosans can be checked in Figure 2. Sample F1, corresponds to sample 21 (see Table 1), shows that the different aggregates formed, are much more compact. On the other hand, sample F2, which is obtained by the combination 18 (see Table 1), lavender oil has not been able to incorporate into the micellar system.

When dealing with sample 23 (see Table 1), that corresponds to F3 in Figure 2, the different layers promoted by the controlled addition of polymers can be, clearly, observed. The nucleus where the micellar system has formed micelle units, with the essential oil and the surfactant and the different layers formed through the addition of the different chitosans. The outermost layer corresponds to soluble chitosan and the innermost layer is formed by the insoluble chitosan. Sample 19 (see Table 1) that corresponds to the legend F4 (Figure 2), surfactant molecules are, again dispersed by the microcapsule structure, together with the polymers used.

\subsection{Particle Size}

The different samples obtained, have been compared. Samples containing active ingredient (lavender oil) show a narrow peak on particle size distribution. The system formed is much more compact and where they have formed a micellar system between the essential oil and the surfactant, the size distribution is more regular. As can be seen in Graph 1, all the samples can be compared with the use or not of active ingredient when using Tween 20. The molecular interactions between the organic compounds of essential oil and surfactant, as well as the interactions between the organic chains of it, can explain their effects on size reducing considerably.

In the case of the samples, with and without the active ingredient, and using the two surfactants, the size effect can be observed in Graph 2. The use of the two surfactants with active ingredient usually gives a reduced size due to the hybrid-micellar system that has been formed, while the absence of the essential oil causes a distortion to the system, giving an expansion in it is size. The use of anionic surfactant (LSS) with non-ionic surfactant (Tween 20) provokes a less strong interaction, not only in their organic part, but also in the more polar head of their chemical structures (Sulfate group in LSS and ethoxylated groups in Tween 20).

When using soluble chitosan in the structure formed (samples 17 - 24), some different peaks have been obtained. These size differences can be attributed to the formation of molecular aggregates with micelles, due to the distribution of polarity among the polymeric chitosan chains.
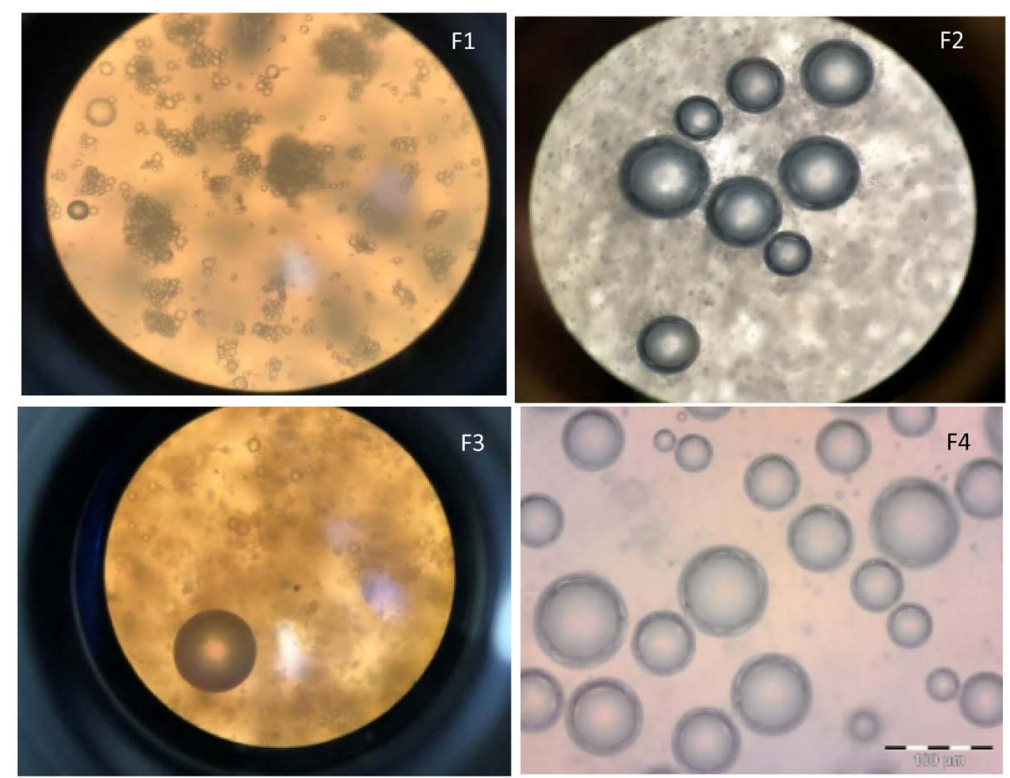

Figure 2. F1: Sample 21 (5x); F2: Sample 18 (10x); F3: Sample 23 (10x); F4: Sample 19 (10x). 


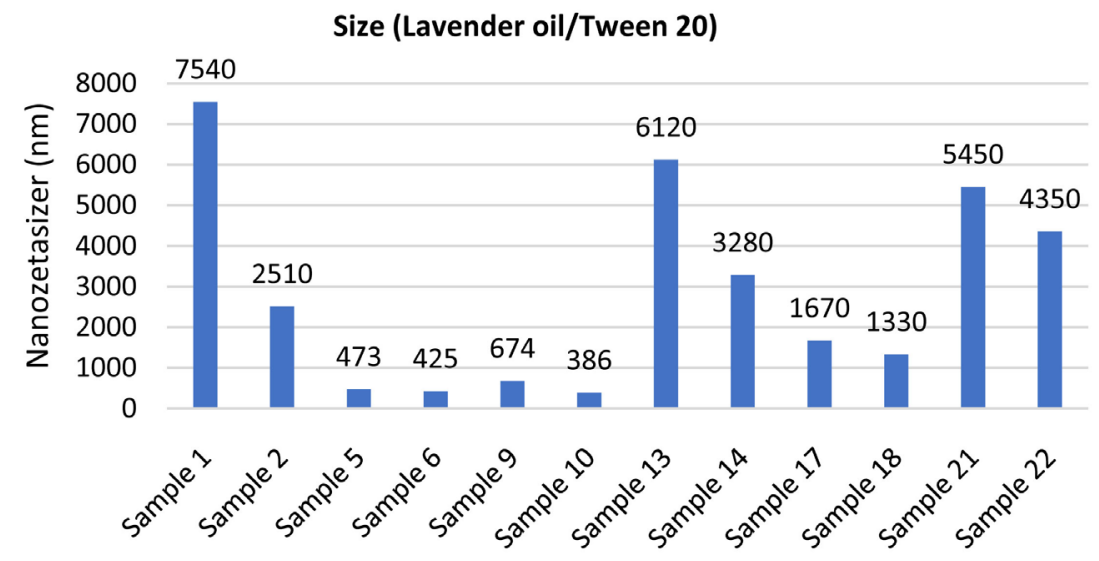

Graph 1. Size effects of lavender oil and Tween 20 with the zeta sizer.

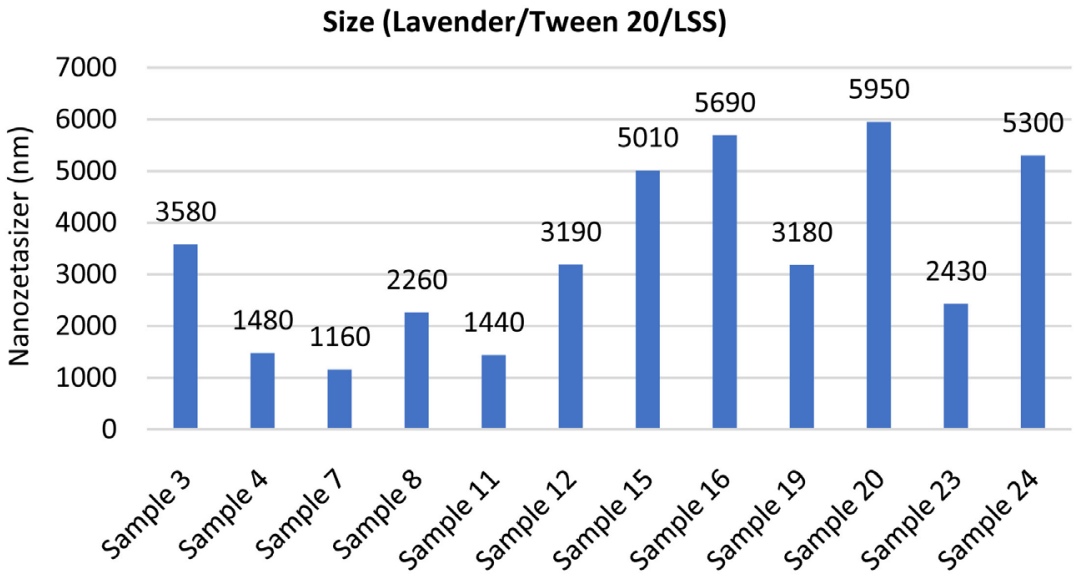

Graph 2. Size effects of lavender, Tween 20 and LSS with the zeta sizer.

\subsection{Zeta Potential}

When dealing with the modification of Zeta Potential on the surface of the self-assembly elements in every sample, it has been compared exactly as in point 3.2. The samples were made with active ingredient and Tween 20 and without essential oil. As it can be observed in Graph 3, odd samples have a higher value than even samples. The odd-numbered samples refer to those in which the active ingredient has been added and the formation of micelles with the chemical components of the essential oil, gives these structures higher stability. High values of Zeta Potential (with positive or negative sign) mean that the structure formed is stable enough to be considered as nucleus of stabilization of the microcapsule.

The stability of the system, as well as in the case of size measurements, molecular interactions in the different parts of the chemical structure of the surfactant and the essential oil compounds are responsible for these results. The effects on Zeta Potential with the use of the two surfactants, can be checked in Graph 4. The presence of active ingredient, brings regularity to the system. Samples 17 - 24 (with soluble chitosan), show higher values due to the great stability it gives to the system. In spite of the evolution in size, this stability gives a more promising combination to be used as trigger mechanism in the delivery of the microcapsules formed.

\subsection{Percentage Imbibed in the Tissue}

Following the methodology described (2.7) and the application of Equation (1), it has been possible to calculate the percentage by weight of all impregnations of the different samples. 


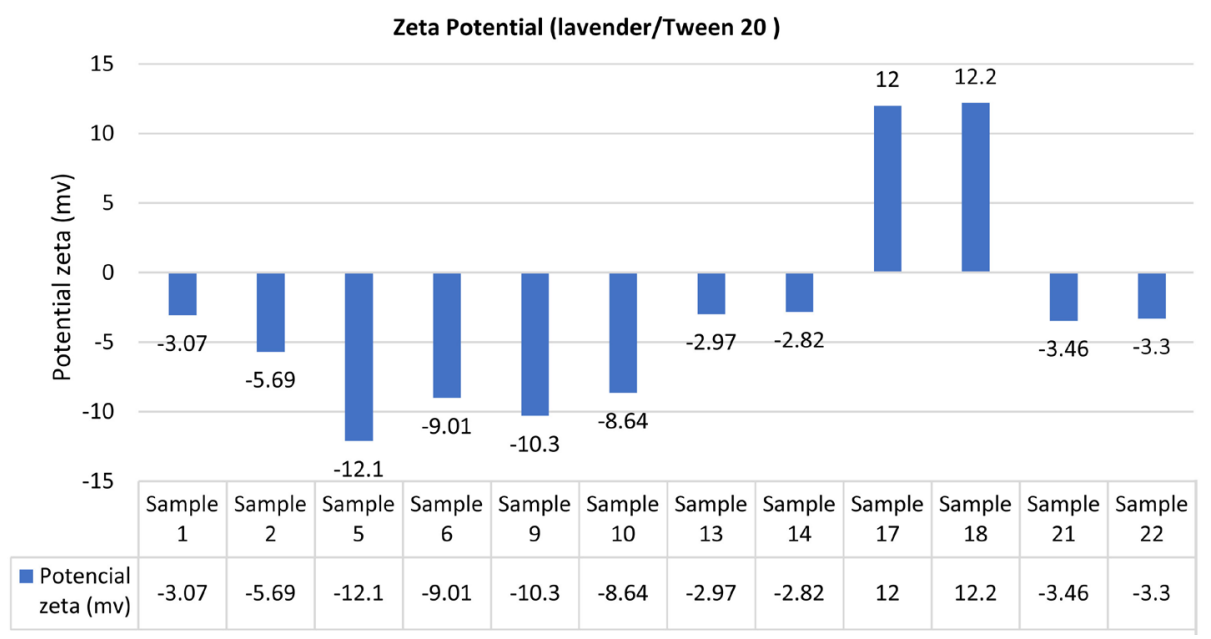

Graph 3. Zeta potential effects of lavender oil and Tween 20.

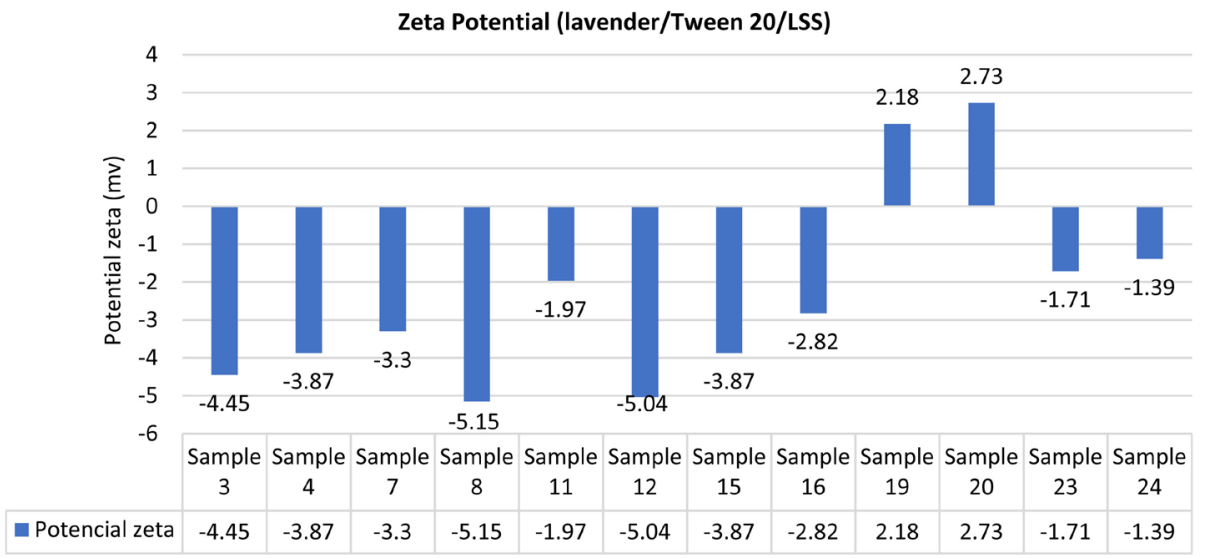

Graph 4. Zeta potential effects of lavender, Tween 20 and LSS.

As can be seen in Graph 5, the impregnation percentage obtained in cotton fabrics is higher in every sample of microcapsules tested. Cotton in water, shows a more polar character and therefore is easier than microcapsules to remain retained inside fibers and in consequence, react better with it than what occurs in polyester. The chemical character of fibers, obviously plays a very important role when dealing with the absorption of microcapsules, although both fibers have been submitted to the same pressing conditions.

\subsection{Antibacterial Test}

The antibacterial effect has been possible to check. More amount of microcapsules remaining into the fiber structure, can show more antimicrobial effect. Nevertheless, the composition of microcapsules, as well as the presence of soluble chitosan (as trigger mechanism) can modify the delivery mechanisms that can occur into the agar plates. As can be seen in Figure 3, where F1 refers to the sample impregnated with polyester fabric, and F2 is the sample impregnated with cotton.

The cotton-impregnated samples show better antimicrobial activity; the amount of active ingredient is higher what gives to samples more possibilities to inhibit the growth of bacteria. In the case of polyester, bacteria grew on the fabric and this has happened in all the samples previously impregnated in that type of fiber. Samples impregnated using cotton fabrics, the percentage by weight of microcapsules retained were higher than in the case of polyester, which has an influence since the amount of microcapsules that can act, are fewer. 


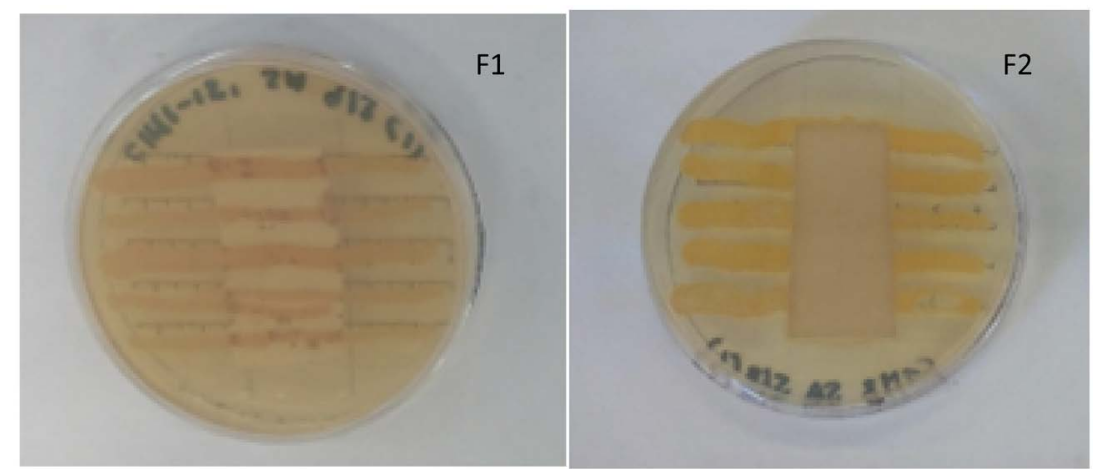

Figure 3. F1: Microbiology test previously impregnated to the polyester fabric; F2: Microbiology test previously impregnated to the cotton fabric.

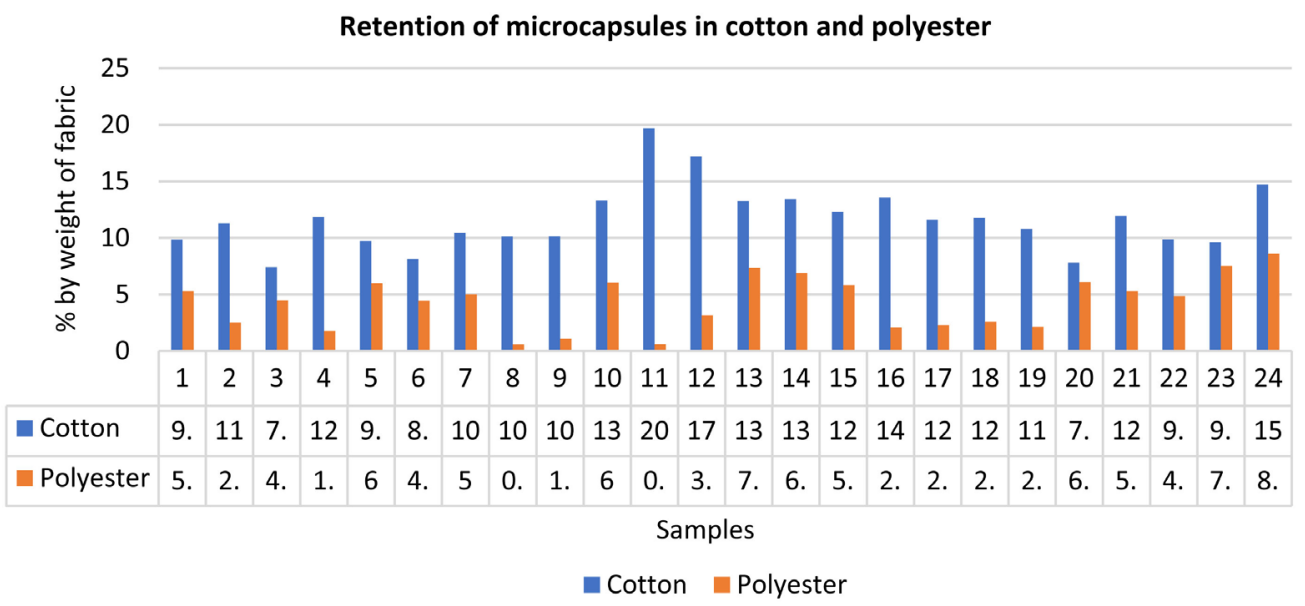

Graph 5. Retention of microcapsules to the fabric in cotton and polyester.

\section{CONCLUSIONS}

Essential oil (Lavender) microcapsules, based on chitosan polymer combination, with antimicrobial character have been obtained. Different samples have been obtained using different chitosan structures; some of them are insoluble, and in some cases, a trigger mechanism can be added using soluble chitosan modified polymers.

The use of a surfactant causes, due to the formation of micelles, increases the molecular interactions allowing the oil to be immobilized in the nucleus. Tween 20 causes a reduction in sample size, while the addition of LSS causes a distortion on the self-assembly effect of micelles.

When applied to fabrics using padding machine at the same level of pressing effects, samples imbibed into cotton show good results in the antimicrobial test. High molecular weight chitosan polymers show stronger interactions inside the shell phase that causes a reduction in the antibacterial effect. On the other hand, when a low molecular weight chitosan is used, the interaction is weaker causing a rapid effect on the growth of bacteria.

There is a different effect of the same microcapsules when the textile substrate is changed. Absorption characteristics of it influence a lot on the amount of microcapsules retained into the tissue that is translated to a less effective antimicrobial effect.

\section{ACKNOWLEDGEMENTS}

Authors want to show their acknowledgements to the institutions and companies that helped to the 
development of this work. Spanish Ministry of Science and Technology. TEXBICO (RTI2018-094014-B-100) that granted the necessary funds to do the experimental work and Biomedical Chitosan (Australia) and CHIBIO (China), for kindly supply the samples used in the Shell structure of microcapsules.

\section{CONFLICTS OF INTEREST}

The authors declare no conflicts of interest regarding the publication of this paper.

\section{REFERENCES}

1. Avila-Figueroa, R., Ramírez-Galvan, L. and Alpuche-Aranda, C. (1986) Infecciones nosocomiales en un hospital pediátrico. Salud Publica de Mexico, 28, 616-622.

http://saludpublica.mx/index.php/spm/article/view/319

2. Hedlund, K.-O., Nordgren, J., Svensson, L., Nybom, R., Hagbom, M. and Wigzell, H. (2015) Ionizing Air Affects Influenza Virus Infectivity and Prevents Airborne-Transmission. Scientific Reports, 5, Article No. 11431. https://doi.org/10.1038/srep11431

3. Martínez, J.M.A. (2015) Trabajo fin de grado infecciones nosocomiales: Pseudomonas aeruginosa y su importancia, sus características y su.

4. Massella, D., Giraud, S., Guan, J.P., Ferri, A. and Salaün, F. (2019) Manufacture Techniques of Chitosan-Based Microcapsules to Enhance Functional Properties of Textiles. In: Crini, G. and Lichtfouse, E., Eds., Sustainable Agriculture Reviews 35, Springer, Berlin, 303-336. https://doi.org/10.1007/978-3-030-16538-3 8

5. Jyothi Sri, S., Seethadevi, A., Suria Prabha, K., Muthuprasanna, P. and Pavitra, P. (2012) Microencapsulation: A Review. International Journal of Pharma and Bio Sciences, 3, 509-531.

6. Carmona, C.G. (2019) Desarollo de Microcápsulas Rígidas de Fragancia y de Técnicas Que Permitan La Cuantificación de La Eficiencia de Encapsulación. Ph.D. Thesis, UPC, 253.

7. Chinta, S.K. and Pooja, P.W. (2013) Use of Microencapsulation in Textiles. Indian Journal of Engineering, 3, 37-40.

8. Sharkawy, A., Fernandes, P., Barreiro, M., Rodrigues, E. and Shoeib, T. (2017) Aroma-Loaded Microcapsules with Antibacterial Activity for Eco-Friendly Textile Application: Synthesis, Characterization, Release and Green Grafting. Industrial \& Engineering Chemistry Research, 56, 19. https://doi.org/10.1021/acs.iecr.7b00741

9. Lozano Berna, M. (2009) Obtención de Microencapsulados Funcionales de Zumo de Opuntia Stricta Mediante Secadso Por Atomización. PFC. Ingeniería Técnica Industrial, Especialidad En Química Industrial. Universidad Politécnicade Cartagena, 69.

10. Theisinger, S., Schoeller, K., Osborn, B., Sarkar, M. and Landfester, K. (2009) Encapsulation of a Fragrance via Miniemulsion Polymerization for Temperature-Controlled Release. Macromolecular Chemistry and Physics, 210, 411-420. https://doi.org/10.1002/macp.200800499

11. Liu, X., Huang, L.Y., Chen, H.Y., Qian, M.C. and Ji, H.B. (2020) Pore Size Matching Up: A Novel Insight into Cotton Textile Aromatic Finishing. Flavour and Fragrance Journal, 35, 149-156. https://doi.org/10.1002/ffj.3546

12. Zhang, Z., Chen, L., Ji, J., Huang, Y. and Chen, D. (2003) Antibacterial Properties of Cotton Fabrics Treated with Chitosan. Textile Research Journal, 73, 1103-1106. https://doi.org/10.1177/004051750307301213

13. Xiao, Z., Liu, W., Zhu, G., Zhou, R. and Niu, Y. (2014) Production and Characterization of Multinuclear Microcapsules Encapsulating Lavender Oil by Complex Coacervation. Flavour and Fragrance Journal, 29, 166-172. https://doi.org/10.1002/ffj.3192

14. Yang, Z., Peng, Z., Li, J., Li, S., Kong, L., Li, P. and Wang, Q. (2014) Development and Evaluation of Novel Flavour Microcapsules Containing Vanilla Oil Using Complex Coacervation Approach. Food Chemistry, 145, 
272-277. https://doi.org/10.1016/j.foodchem.2013.08.074

15. Álvarez-Paino, M., Muñoz-Bonilla, A. and Fernández-García, M. (2017) Antimicrobial Polymers in the Nano-World. Nanomaterials, 7, 48. https://doi.org/10.3390/nano7020048

16. Ramesh, H.P. and Tharanathan, R.N. (2003) Carbohydrates-The Renewable Raw Materials of High Biotechnological Value. Critical Reviews in Biotechnology, 23, 149-173. https://doi.org/10.1080/713609312

17. Gupta, K.C. and Ravi Kumar, M.N.V. (2016) An Overview on Chitin and Chitosan Applications with an Emphasis on Controlled Drug Release Formulations. Macromolecular Chemistry and Physics, 40, 273-308. https://doi.org/10.1081/MC-100102399

18. Berghoff, C.F. (2011) Desarrollo y Caracterización de Matrices Compuestas Quitosano/Polimero Sintetico Para Regeneración de Tejido Óseo. 1-229.

19. Zargar, V., Asghari, M. and Dashti, A. (2015) A Review on Chitin and Chitosan Polymers: Structure, Chemistry, Solubility, Derivatives, and Applications. ChemBioEng Reviews, 2, 204-226.

https://doi.org/10.1002/cben.201400025

20. Rinaudo, M. (2006) Chitin and Chitosan: Properties and Applications. Progress in Polymer Science (Oxford), 31, 603-632. https://doi.org/10.1016/j.progpolymsci.2006.06.001

21. Yi, H., Wu, L.Q., Bentley, W.E., Ghodssi, R., Rubloff, G.W., Culver, J.N. and Payne, G.F. (2005) Biofabrication with Chitosan. Biomacromolecules, 6, 2881-2894. https://doi.org/10.1021/bm0504101

22. Yang, Z., Zeng, Z., Xiao, Z. and Ji, H. (2014) Preparation and Controllable Release of Chitosan/Vanillin Microcapsules and their Application to Cotton Fabric. Flavour and Fragrance Journal, 29, 114.

https://doi.org/10.1002/ffj.3186

23. Hebeish, A., Abdel-Mohdy, F.A., Fouda, M.M.G., Elsaid, Z., Essam, S., Tammam, G.H. and Drees, E.A. (2011) Green Synthesis of Easy Care and Antimicrobial Cotton Fabrics. Carbohydrate Polymers, 86, 1684-1691. https://doi.org/10.1016/j.carbpol.2011.06.086

24. El-tahlawy, K.F., El-bendary, M.A., Elhendawy, A.G. and Hudson, S.M. (2005) The Antimicrobial Activity of Cotton Fabrics Treated with Different Crosslinking Agents and Chitosan. Carbohydrate Polymers, 60, 421-430. https://doi.org/10.1016/j.carbpol.2005.02.019

25. Mourya, V.K. and Inamdar, N.N. (2008) Chitosan-Modifications and Applications: Opportunities Galore. Reactive and Functional Polymers, 68, 1013-1051. https://doi.org/10.1016/j.reactfunctpolym.2008.03.002

26. Butstraen, C. and Salaün, F. (2014) Preparation of Microcapsules by Complex Coacervation of Gum Arabic and Chitosan. Carbohydrate Polymers, 99, 608-616. https://doi.org/10.1016/j.carbpol.2013.09.006

27. López, A., et al. (2019) Production and Evaluation of Antimicrobial Microcapsules with Essential Oils Using Complex Coacervation. Journal of Biomedical Science and Engineering, 12, 377-390.

https://doi.org/10.4236/jbise.2019.128029

28. AATCC American Association of Textile Chemists and Colorists (2015) AATCC-Technical Manual. AATCC, 90, 512.

29. AATCC Test Method (2010) Antibacterial Finishes on Textile Materials: Assessment of. AATC Technical Manual, 1988, 142-144.

30. Fan, F., Zhang, W. and Wang, C. (2015) Covalent Bonding and Photochromic Properties of Double-Shell Polyurethane-Chitosan Microcapsules Crosslinked onto Cotton Fabric. Cellulose, 22, 1427-1438.

https://doi.org/10.1007/s10570-015-0567-5 